\title{
IDENTIFIKASI REKAHAN DANGKAL AKIBAT AKTIVITAS LUMPUR SIDOARJO DI KECAMATAN TANGGULANGIN - KABUPATEN SIDOARJO MENGGUNAKAN METODE GROUND PENETRATING RADAR (GPR)
}

\author{
Ilham Adi Pratama ${ }^{1)}$, Dwa Desa Warnana ${ }^{1)}$, Firman Syaifuddin ${ }^{1)}$ \\ ${ }^{1}$ Teknik Geofisika, Fakultas Teknik Sipil dan Perencanaan, Instittut Teknologi Sepuluh Nopember \\ Email: Ilham.adhy@gmail.com
}

\begin{abstract}
Abstrak.Rencana pengeboran sumur gas baru PT. Lapindo Brantas di Tanggulangin, Sidoarjo dinilai beresiko karena lokasinya yang dekat dengan pusat semburan yang telah rusak dan masih sangat rawan, sehingga masih ada potensi keluarnya semburan di area tanggul dan sekitarnya jika dibor. Selain itu, aktivitas lumpur sidoarjo menyebabkan kondisi bawah permukaan di daerah penelitian menjadi rentan terhadap resiko rekahan dan penurunan tanah. Oleh sebab itu, perlu dilakukan penelitian tentang kondisi bawah permukaan dangkal menggunakan metode Ground Penetrating Radar (GPR) yang bertujuan untuk mendeteksi rekahan dangkal yang berada di sekitar daerah rencana pengeboran. Metode GPR dipilih karena dapat memetakan kondisi bawah permukaan yang dangkal secara terperinci dengan resolusi yang tinggi. Berdasarkan hasil penelitian ini, diketahui bahwa pada daerah rencana pengeboran terdapat banyak rekahan berpola radial dengan arah barat daya-timur laut dan rekahan berpola melingkar (circular) yang berarah barat laut-tenggara. Kondisi tersebut membuat daerah bawah permukaan di sekitar lokasi rencana pengeboran menjadi tidak stabil dan berisiko karena dapat menyebabkan penurunan tanah di daerah sekitar dan dikhawatirkan dapat memperluas semburan lumpur panas pada daerah penelitian.
\end{abstract}

Kata Kunci: Rekahan, Lumpur Panas, GPR

\begin{abstract}
PT. Lapindo Brantas's new gas well drilling has potential risk because the location was so closed with the central of mud volcano eruption that already broken and risky. Further breakouts of mud are still possible in embankment and around if there is drilling activity. Sidoarjo mud activities also causing subsurface conditions research area becomes vulnerable to the risk of fractures and land subsidence. Therefore, there should be a study about shallow subsurface conditions using Ground Penetrating Radar (GPR) which aims to detect shallow fracture in the surrounding area of PT. Lapindo Brantas's new gas well drilling plan in Tanggulangin, Sidoarjo. GPR method chosen because it can mapping the shallow subsurface in detail with high resolution. Based on the observation result, it is known that there are lot of fracture with two types, first is radial type with south west-north east direction and second is circular type with north west-south east direction. Fractures show that shallow subsurface condition in PT. Lapindo Brantas's new gas well drilling is very risky because it can lead to decreased land deeper and feared to expand the mud flow in Sidoarjo area.
\end{abstract}

Keywords:Fractures, Mud Volcano, GPR

\section{PENDAHULUAN}

Pada awal tahun 2016, PT. Lapindo Brantas berencana melakukan pengeboran sumur gas baru di daerah Tanggulangin, Sidoarjo. Lokasi pengeboran ini berjarak sekitar tiga kilometer dari pusat semburan utama, sehingga dinilai memiliki resiko yang tinggi yang dapat mengakibatkan meluasnya semburan lumpur panas ke daerah tersebut. sehingga perlu dilakukan penelitian dengan menggunakan metode geofisika untuk mengetahui kondisi bawah permukaan dangkalseperti rekahan pada daerah pengeboran sumur gas baru tersebut.
Penelitian ini bertujuan untuk mengidentifikasi posisi dan pola rekahan pada daerah penelitian sehingga dapat digunakan untuk mengetahui pengaruh rekahan yang ada terhadap kondisi tanah di daerah pengeboran sumur gas baru sehingga dapat diketahui tingkat resiko yang timbul jika pengeboran sumur gas baru milik PT Lapindo Brantas tetap dilakukan.

Metode geofisika yang cocok untuk memetakan rekahan adalah Ground Penetrating Radar (GPR), karena mampu memetakan kondisi bawah permukaan yang dangkal secara terperinci dengan resolusi yang tinggi(Handoko dkk., 2010). 
Pada penelitian ini, kedalaman yang dapat dipertanggungjawabkan adalah 35 meter.

\section{TINJAUAN PUSTAKA}

\section{Geologi Regional}

Batuan di daerah Sidoarjo disusun oleh lapisan batuan sedimen yang terdiri dari batulanau, batulempung, batuserpih, batupasir dan batugamping. Umur batuan sedimen tersebut berkisar antara Miosen Awal hingga Resen. Formasiformasi batuan di daerah Sidoarjo secara geologi regional termasuk ke dalam zona depresi Kendeng. Pada zona depresi ini terbentuk beberapa anticlinorium (Smiyth dkk, 2008).

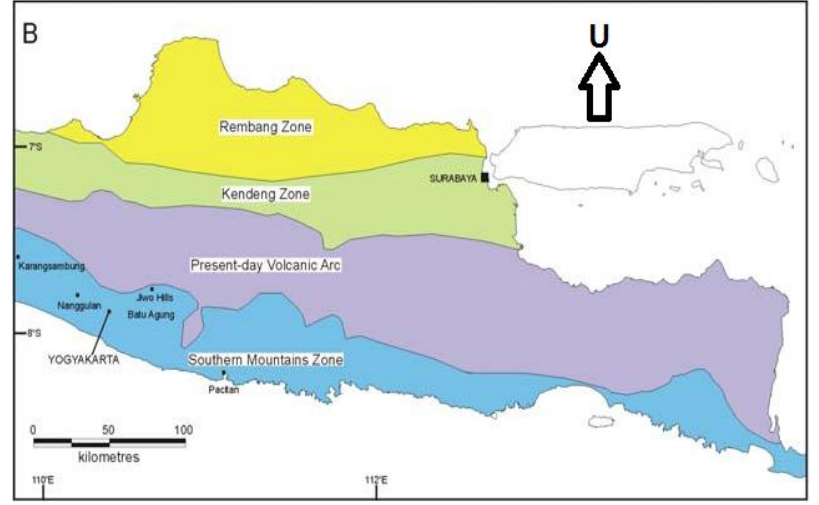

Gambar 1 Zona Stratigrafi dan Struktur Pulau Jawa Menurut van Bemmelen, 1949 (Smiyth dkk, 2008).

\section{Metode Ground Penetrating Radar (GPR)}

Ground Penetrating Radar (GPR) merupakan suatu metoda pengukuran geofisika yang menggunakan sinyal gelombang elektromagnetik dalam prinsip kerjanya. Metode GPR didasarkan atas persamaan Maxwell yang merupakan perumusan matematis untuk hukum-hukum alam yang berkaitan dengan semua fenomena elektromagnetik yang menjelaskan bagaimana medan listrik dan medan magnet dapat terjadi. Persamaan Maxwell untuk medium isotropic heterogen dirumuskan sebagai berikut:

$$
\nabla \cdot H=\frac{\partial D}{\partial t}+J
$$

dengan hubungan $D=\varepsilon_{o} E, B=\mu_{o} H, J=\sigma E$

$$
\begin{aligned}
\nabla \cdot B & =0 \\
\nabla \cdot E & =\frac{\rho}{\varepsilon_{o}}
\end{aligned}
$$

$$
\begin{aligned}
& \nabla \times B=\mu_{o} \varepsilon_{o}-\frac{\partial B}{\partial t} \\
& \nabla \times E=-\frac{\partial B}{\partial t}
\end{aligned}
$$

dimana $\mathrm{E}$ dan $\mathrm{H}$ adalah intensitas medan listrik dan magnet dan diukur dalam [volt/m] dan [ampere/m]. D dan B adalah kerapatan fluks listrik dan magnetik yang diukur dalam [coulomb/m ${ }^{2}$ ] dan [weber $/ \mathrm{m}^{2}$ atau tesla]. $\rho$ dan J adalah tahanan jenis dan kerapatan arus listrik yang diukur dalam satuan [ohm.m] dan [ampere/m²], sedangkan besaran $\varepsilon_{0}$ dan $\mu_{0}$ adalah permitivitas dan permeabilitas dalam ruang hampa yang bernilai $8.854 \times 10^{-12} \mathrm{farad} / \mathrm{m}$ dan $4 \pi \times 10^{-7}$ henry/m, sedangkan besaran $\sigma$ adalah konduktivitas yang diukur dalam satuan [S/m] (Orfanidis, 2002).

Menggunakan persamaan Maxwell diatas, dapat diturunkan persamaangelombang elektromagnetik sebagai berikut:

$$
\begin{aligned}
& \nabla^{2} E=\mu_{o} \varepsilon_{o} \frac{\partial^{2} E}{\partial t^{2}} \\
& \nabla^{2} H=\mu_{o} \varepsilon_{o} \frac{\partial^{2} E}{\partial t^{2}}
\end{aligned}
$$

dengan kecepatan rambat gelombang di udara dan ruang vakum sebesar:

$c=\frac{1}{\sqrt{\mu_{o} \varepsilon_{o}}} \approx 3,00 \times 10^{8} \mathrm{~m} / \mathrm{s}$

\section{Gelombang Radar}

Radiasi elektromagnetik yang direfleksikan material bergantung pada kontras konstanta dielektrik relatif perlapisan-perlapisan yang berdekatan. Jika kontras tersebut besar, maka jumlah energi gelombang radar yang direfleksikan juga besar. Koefisien refleksi (R) didefinisikan sebagai perbandingan energi yang dipantulkan dan energi yang datang. Besarnya $\mathrm{R}$ ditentukan oleh kontras kecepatan dielektrik relatif dari medium. Dalam semua kasus magnitudo $\mathrm{R}$ berada pada rentang \pm 1 . Bagian energi yang ditransmisikan sama dengan 1-R, sedangkan daya koefisiensi refleksi sama dengan $\mathrm{R}^{2}$.

Amplitudo koefisien refleksi diberikan oleh persamaan berikut:

$$
R=\frac{\left(V_{1}-V_{2}\right)}{\left(V_{1}+V_{2}\right)}=\frac{\sqrt{\varepsilon_{2}}-\sqrt{\varepsilon_{1}}}{\sqrt{\varepsilon_{2}}+\sqrt{\varepsilon_{1}}}
$$

ngan $\mathrm{V}_{1}$ dan $\mathrm{V}_{2}$ adalah kecepatan gelombang radar pada lapisan 1 dan $2\left(\mathrm{~V}_{1}<\mathrm{V}_{2}\right)$, dan $\varepsilon_{1}, \varepsilon_{2}$ adalah 
konstanta dielektrik relatif $\left(\varepsilon_{\mathrm{r}}\right)$ dari lapisan 1 dan lapisan 2.Kecepatan gelombang elektromagnetik pada berbagai medium bergantung pada kecepatan cahaya di udara, konstanta dielektrik relatif $\left(\varepsilon_{r}\right)$, dan permeabilitas magnetik ( $\mu_{r}=1$ untuk materi non magnetik). Selain itu, kecepatan gelombang elektromagnetik tergantung pada jenis bahan dan merupakan fungsi dari permitivitas relatif bahan. Kecepatan gelombang elektromagnetik dalam material $\left(\mathrm{V}_{\mathrm{m}}\right)$ dirumuskan dalam persamaan beikut (Reynold, 1997):

$$
V_{m}=\frac{c}{\sqrt{\left[\left(\frac{\varepsilon_{r} \mu_{r}}{2}\right)\left(1+P^{2}\right)-1\right]}}
$$

mana $_{\mathrm{m}}$ adalah kecepatan gelombang elektromagnetik, c adalah kecepatan cahaya, $\varepsilon_{\mathrm{r}}$ adalah konstanta dielektrik relatif, $\mu_{r}$ adalah permeabilitas magnetik relatif (henry/m) dan $P$ adalah loss factor $\left(\frac{\sigma}{\omega \varepsilon}\right)$.Untuk material dengan loss factor rendah $(P \approx 0)$, maka berlaku persamaan:

$$
V_{m}=\frac{c}{\sqrt{\varepsilon_{r}}}=\frac{0.3}{\sqrt{\varepsilon_{r}}} m / n s
$$

\section{METODOLOGI PENELITIAN}

Lokasi penelitian ini berada di sekitar daerah pengeboran sumur gas baru di Tanggulangin, Sidoarjo, Jawa Timur. Dimana titik Tanggulangin 6 dan Tanggulangin 10 merupakan daerah yang akan dilakukan pengeboran sumur gas baru Lapindo.

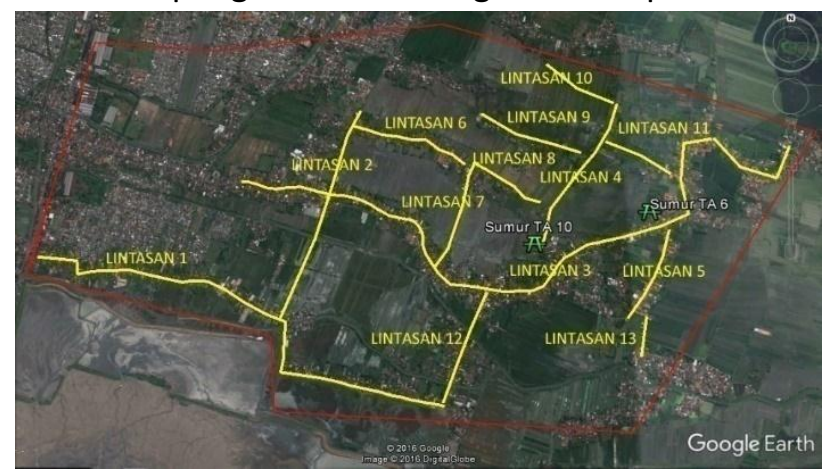

Gambar 2Lintasan pengukuran GPR (lintasan 1-5) dan lokasi rencana pengeboran (Sumur TA 6 dan 10) (Earth, 2016)

Pengambilan data yang dilakukan pada tanggal 20-25 April 2016. Data GPRtersebut kemudian diolah berdasarkan diagram alir sebagai berikut.

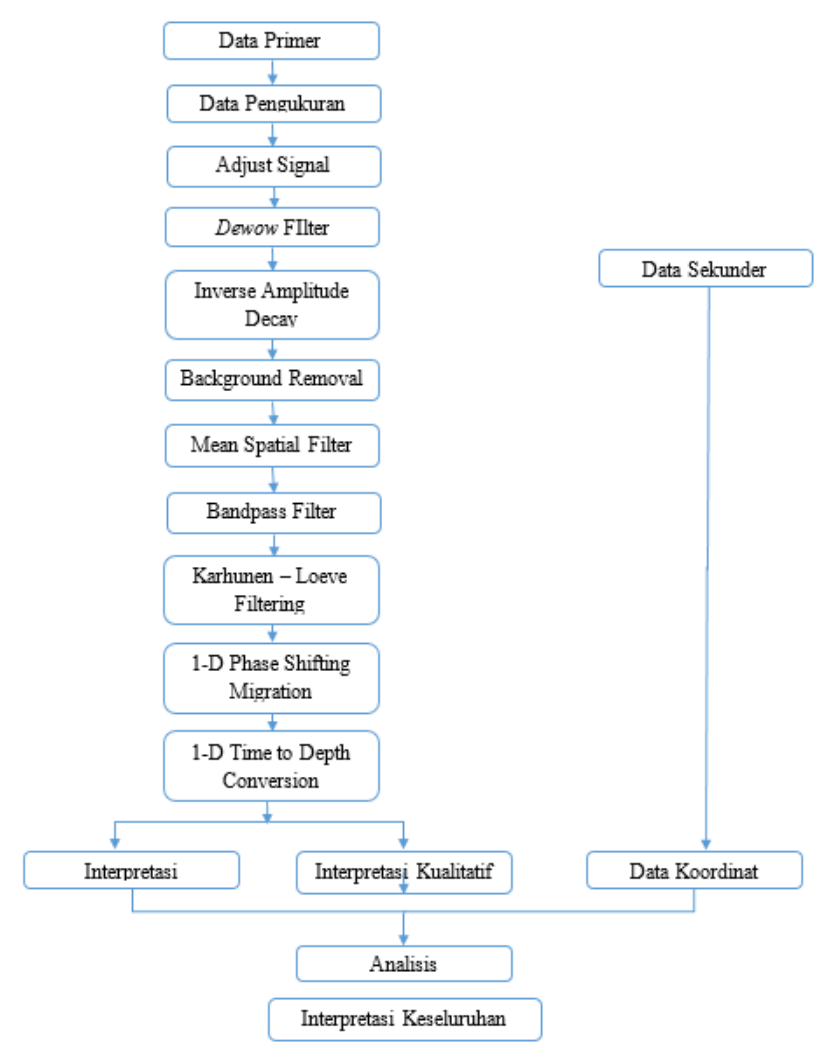

Gambar 3 Diagram Alir Pengolahan Data GPR

Adjust Signal Position digunakan untuk menghilangkan waktu jeda antara sinyal yang terbaca pertama hingga sampai pada kontras lapisan permukaan tanah. Poses filteing digunakan untuk menghilangkan berbagai frekuensi lateral dan horizontal. Proses inverse amplitude decay dilakukan untuk meningkatkan gain, peningkatan gain dilakukan karena sinyal radar sangat cepat teratenuasi ketika menjalar ke dalam permukaan bumi, sehingga sinyal dari kedalaman yang lebih tinggi menjadi sangat kecil/lemah dan informasi yang berasal dari sinyal lemah tersebut tidak begitu terlihat. Proses 1-D Phase Shifting Migration ini digunakan untuk memindahkan data GPR ke posisi yang benar secara horizontal maupun vertikal. Ketidakpastian posisi ini disebabkan oleh efek difraksi yang terjadi ketika gelombang elektromagnetik mengenai ujung atau puncak suatu diskontinuistas akibat perbedaan struktur geologi seperti sesar atau lipatan, dan 1-D Time to Depth Conversion merupakan proses konversi data GPR dari domain waktu menjadi domain kedalaman. Hal ini dilakukan untuk mendapatkan kedalaman sebenarnya dari data penampang. 


\section{HASIL DAN PEMBAHASAN}

\section{IdentifikasiRekahan}

Parameter pertama yang digunakan sebagai dasar penentuan lokasi dan arah rekahan adalah pola diskontinuitas structural yang dapat diamati secara langsung pada radargram serta data dari kondisi di lapangan saat pengambilan data, seperti adanya jembatan atau sawah. Parameter kedua adalah struktur geologi di lokasi penelitian sehingga dapat diketahui pola dan arah rekahan pada struktur geologi tersebut, di mana struktur geologi akan menjadi parameter untuk mengonfrmasi rekahan yang ditentukan oleh parameter diskontinuitas. Menurut penelitian yang dilakukan Yin dan Jr pada tahun 2004, struktur yang menembus (piercement structure) yang aktif memiliki pola rekahan yang circular (melingkar) dan radial (menjari) dengan model ditunjukan oleh gambar 4:
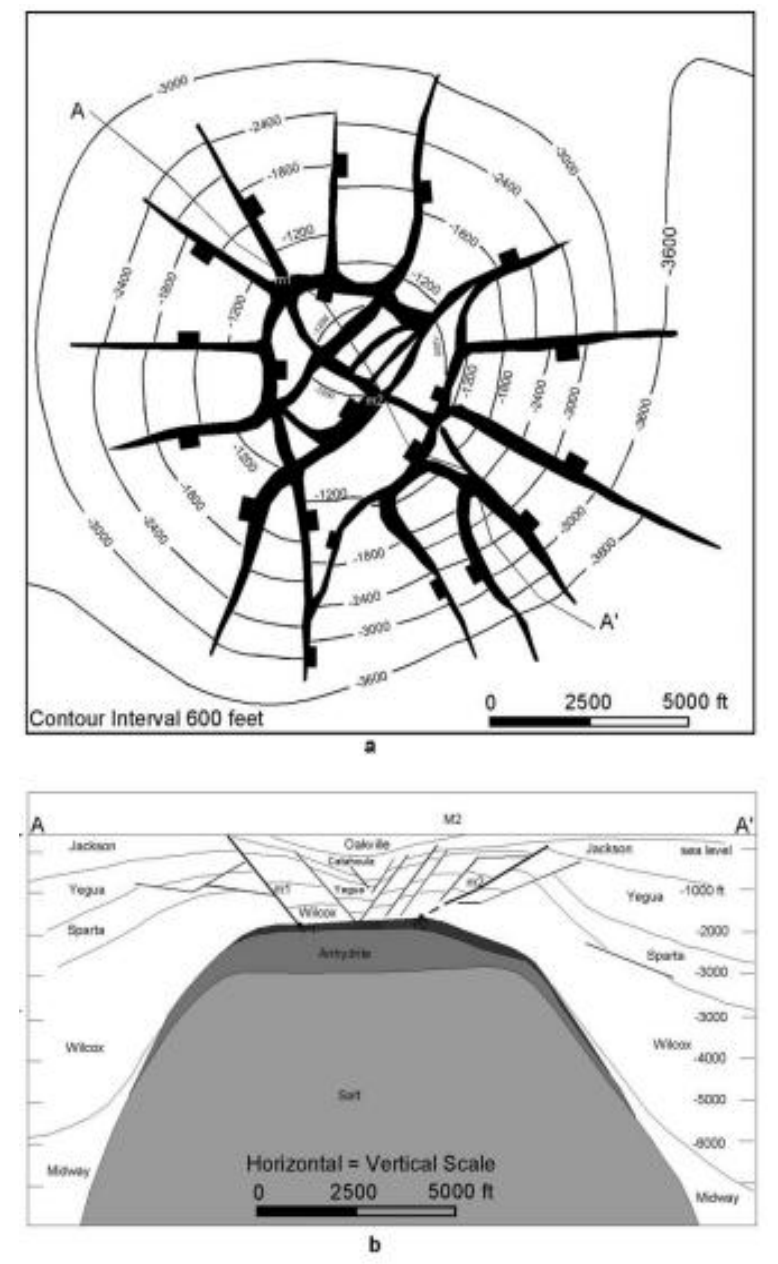

Gambar 4 (a) Contoh pola rekahan pada struktur menembus aktif (active piercement structures) tampak atas, (b) penampang bawah permukaan dari pola rekahan pada stuktur menembus aktif (active piercement structures) (Yin \& Jr, 2004).

Struktur geologi di Lumpur Sidoarjo (Lusi) dapat dianalogikan memiliki model yang serupa dengan Gambar 4 karena menurut penelitian Mazzini et al tahun 2009 yang menginterpretasikan data seismik yang melintasi lokasi semburan Lumpur Sidoarjo menyatakan bahwa terdapat struktur menembus (piercement structure) yang kompleks sebagai struktur geologi Lumpur Sidoarjo.

\section{Analisis Rekahan}

Lintasan yang berorientasi barat timur dan berada di utara pusat semburan Lusi, dapat mengidentifikasi rekahan pada jalur selatan-utara, tenggara-barat laut, dan barat daya-timur laut yang akan tampak pada radargram. Lintasan yang berorientasi selatan utara dan berada di utara pusat semburan Lusi, hanya akan mengidentifikasi rekahan yang berada pada jalur barat hingga timur.

Gambar 5 merupakan hasil overlay radargram dari seluruh lintasan pengukuran terhadap peta daerah pengukuran. Overlay ini digunakan untuk mengetahui posisi rekahan sebenarnya pada daerah pengukuran. Dari hasil overlay ini, terlihat banyak sekali rekahan-rekahan yang berada di daerah penelitian. Rekahan-rekahan ini merupakan indikator bahwa daerah penelitian ini tidak stabil.

Apabila rekahan pada orientasi yang sama dihubungkan dan di-overlay dengan peta lapisan bawah permukaan, maka terlihat suatu pola rekahan yang terbagi menjadi dua tipe pola rekahan, yaitu pola rekahan circular yang berpola melingkari pusat semburan Lusi dan pola rekahan radial atau menjari, yang mengarah ke pusat semburan Lusi, seperti terlihat polanya pada Gambar 6. Rekahan pada jalur barat daya-timur laut dan berada pada sisi utara pusat stuktur merupakan rekahan jenis radial yang menjalar memanjang relatif lurus dari pusat semburan. Rekahan yang tampak berada pada arah barat laut-tenggara merupakan rekahan circular yang menyebar dan mengelilingi pusat semburan. 
Identifikasi Rekahan Dangkal ...

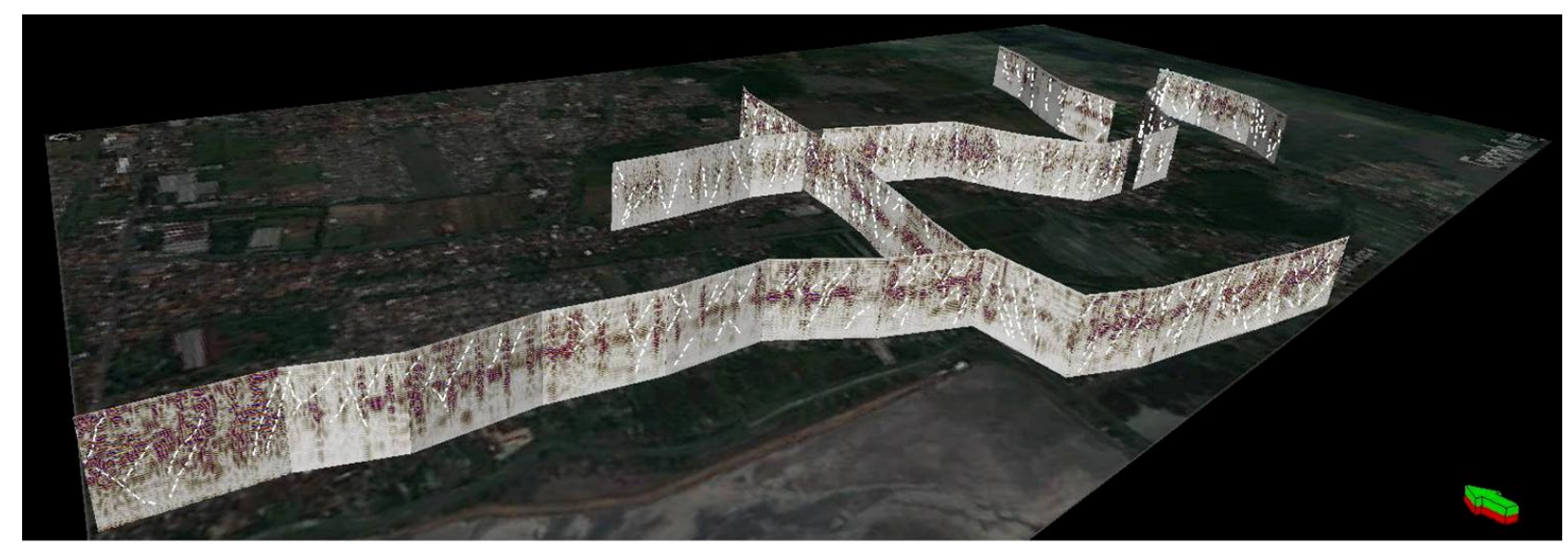

(a)

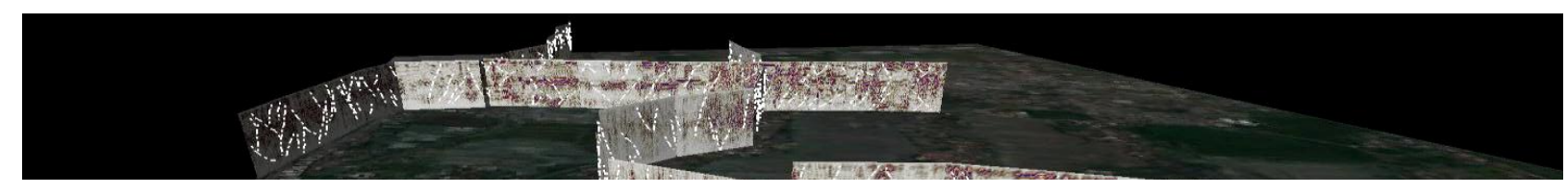




\section{PENUTUP}

\section{Kesimpulan}

Kesimpulan yang didapat dari penelitian ini adalah:

1. Rekahan terlihat pada seluruh radargram lintasan pada kedalaman 0-36 meter dengan panjang rekahan 9-61 meter.

2. Terdapat dua pola rekahan, yaitu rekahan berarah barat daya-timur laut dan berada di utara pusat semburan merupakan jenis rekahan radial yang menjalar lurus atau menjari dari pusat semburan; dan rekahan berarah barat laut-tenggara merupakan jenis rekahan circular yang menyebar seperti lingkaran dari pusat semburan.

\section{Saran}

Saran yang dapat diberikan berdasarkan hasil dan kesimpulan untuk membangun hipotesahipotesa selanjutnya adalah:

1. Untuk mendapatkan hasil yang lebih baik dan akurat terhadap sebaran dan pola rekahan, lintasan pengukuran dapat diperbanyak dengan berbagai variasi orientasi sehingga dapat mengidentifikasi lebih banyak variasi arah rekahan, karena faktor keberhasilan identifikasi rekahan adalah arah pengukuan yang tepat dan sesuai struktur geologi daerah penelitian.

2. Perlu dilakukan penelitian dengan metode geofisika yang lain sebagai pembanding hasil posisi dan letak dari rekahan.

\section{Ucapan Terima Kasih}

Penulis mengucapkan terima kasih kepada dosen pembimbingDr. Dwa Desa Warnana dan Bapak Firman Syaifuddin atas bimbingan dan pengarahan yang diberikan kepada penulis selama proses penelitian hingga penulisan.

\section{DAFTAR PUSTAKA}

Handoko, Godwin, K, B., \& U, H. (2010). Penafsiran Struktur Geologi Bawah Permukaan di Kawasan Semburan Lumpur Sidoarjo, Berdasarkan Penampang Ground Penetrating Radar (GPR). Jurnal Geologi Indonesia, Vol. 5 No. 3, 187-195.
Mazzini, A., Nermoen, A., Krotkiewski, M., Podladchikov, Y., Planke, S., \& Svensen, H. (2009). Strike-slip faulting as a triger mechanism for overpressure release through piercement structure. Implication for the Lusi mud volcano, Indonesia, 1751-1765.

Orfanidis, S. J. (2002). Electromagnetic Waves and Antennas. Piscataway: Rutgers University .

R. Smyth, H., Hall, R., \& J. Nichols, G. (2008). Cenozoic volcanic arc history of East Java, Indonesia: The stratigraphic record of eruptions on an active continental margin. The Geological Society of America, 436.

Reynold, J. M. (1997). An Introduction to Applied and Enviromental Geophysics. England: John Wiley and Sons, inc.

Yin, H., \& Jr, R. H. (2004). Balancing and restoration of piercement structures: geologic insights from 3D kinematic models. Journal of Structural Geology, 99-114. 